\title{
MECHANICAL MILLING OF GAS-ATOMIZED POWDER PREPARED FROM AE42 MAGNESIUM ALLOY
}

\author{
Peter MINÁRIK, Jiří KOZLÍK, Mária ZEMKOVÁ, Robert KRÁL \\ Charles University, Department of Physics of Materials, Prague, Czech Republic, EU, \\ peter.minarik@mff.cuni.cz
}

https://doi.org/10.37904/metal.2019.763

\begin{abstract}
The gas-atomized powder prepared from AE42 magnesium alloy was mechanically milled at various conditions. The effect of milling on the size, morphology and particle microstructure was investigated. It was shown that dry milling at room temperature in argon atmosphere leads to significant refinement of the powder, but the negative effect of cold-welding was observed despite the addition of the process control agent. On the other hand, wet milling in ethanol suppressed the cold-welding and resulted in a significant change of particles morphology from spherical-like to flake-like. The microstructure of powder particles was severely refined, but further investigation by transmission electron microscopy is needed. In addition, it was shown that the continuous oxide layer present on the gas-atomized particles was successfully disrupted by the mechanical milling.
\end{abstract}

Keywords: Magnesium, powder, milling, microstructure

\section{INTRODUCTION}

Powder metallurgy of light metals is in the focus of modern research especially because of continuous need for lighter materials and further development of new sintering and additive manufacturing methods. Magnesium, as the lightest structural material, is of particular interest but the utilization of magnesium powder in a larger scale is still a challenge due to its high reactivity. Metallic powders are prepared by several methods including gas-atomization in argon [1]. Magnesium powder is usually passivated during preparation, nevertheless, it should be handled under a protective atmosphere; otherwise, further oxidation could negatively affect its properties. It was shown that spark plasma sintering (SPS) method, which is also known under a different name - field-assisted sintering technology (FAST), can enhance densification in comparison with others techniques regardless thin oxide layer [2]. However, as shown in the previous study, MgO present on the powder particles prior to the sintering leads to the formation of 3D net-like oxide structure after SPS [3]. This structure is continuous through the whole sample and due to its brittle nature, it facilitates crack propagation during mechanical loading. One of the methods, which are used to enhance mechanical properties of the compacted samples is mechanical milling of the powder, either at room temperature in Ar atmosphere [4] or at cryo-temperature in liquid nitrogen [5]. The microstructure of milled powder is usually significantly refined and the surface of the milled powder is not covered by a continuous layer of oxides.

In this work, powder of magnesium alloy AE42 was mechanically milled in an attritor at room temperature using various conditions. Subsequently, change of powder's size, shape and inner structure upon the milling conditions was investigated.

\section{EXPERIMENTAL METHODS}

The investigated AE42 (Mg-4Al-2RE) magnesium alloy was supplied in the form of gas-atomized powder from TU Clausthal, Germany. The powder consists of particles having size $<80 \mu \mathrm{m}$. Mechanical milling was performed in Union Process 01-HD attritor equipped with stainless-steel shaft and milling tank. The milling was performed at $300 \mathrm{rpm}$, using stainless-steel balls of $6.35 \mathrm{~mm}$ in diameter and the ball-to-powder ratio of 40:1. 
The powder was milled at room temperature either only in Ar atmosphere (dry milling) or in ethanol covered by Ar atmosphere (wet milling). Two milling times were used in this work. $1 \mathrm{~h}$ of milling was selected to observe the initial stage of the milling process. 18 hours of milling was selected upon two previous works, in which saturation of microstructure refinement was observed after approximately $16 \mathrm{~h} \mathrm{[4]} \mathrm{or} 20 \mathrm{~h}$ [6]. $0.5 \mathrm{wt} \%$ of stearic acid (SA) was used as a process control agent to limit cold-welding for the $18 \mathrm{~h}$ batches.

The size and morphology of investigated powder particles were studied by scanning electron microscope ZEISS Auriga Compact. The particles were observed either directly, or embedded into conductive epoxy resin and mechanically ground and polished down to $0.05 \mu \mathrm{m}$ alumina solution.

\section{RESULTS AND DISCUSSION}

Figure 1a shows gas-atomized powder particles of the investigated AE42 magnesium alloy. The particles have a typical round/ellipsoidal shape and their size was mostly in the range of 40-80 $\mu \mathrm{m}$. Nevertheless, smaller particles are also present in a low fraction. The inner structure of the gas-atomized particles is shown in Figure 2a. A fine dendritic microstructure resulting from the fast cooling was observed. The secondary phases were identified as a mixture of $\mathrm{Al}_{11} \mathrm{RE}_{3}$ and $\mathrm{Al} 2 \mathrm{RE}$ phases in the previous study [3].
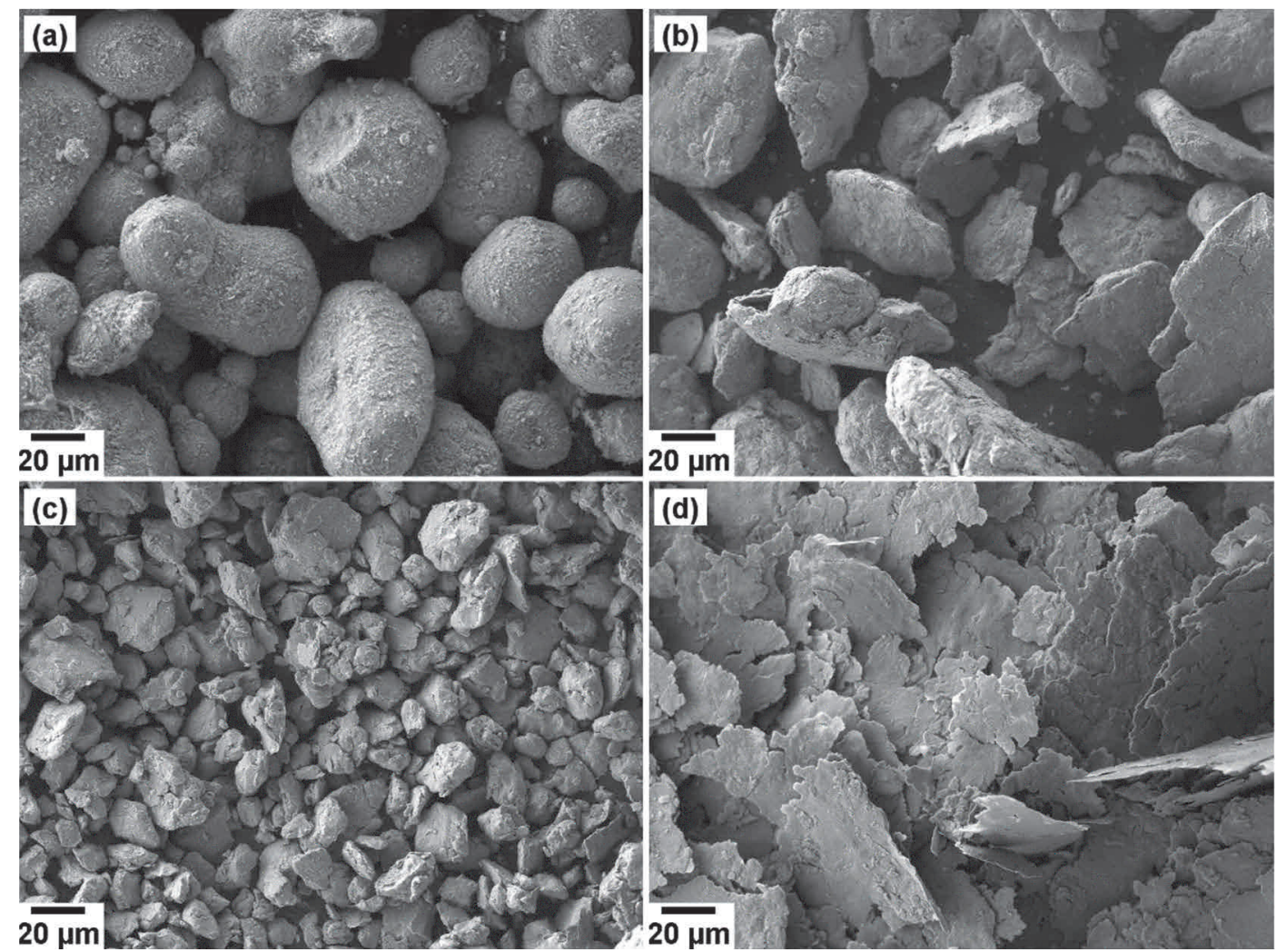

Figure 1 Gas-atomized powder (a), powder milled in Ar for $1 \mathrm{~h}$ (b), in Ar with SA for $18 \mathrm{~h}$ (c) and in Ar with $\mathrm{SA}$ and ethanol for $18 \mathrm{~h}(\mathrm{~d})$.

Mechanical milling performed in attritor resulted in a significant change of the particles' size and morphology. The intensity and nature of these changes highly depend on the milling conditions. Figures $\mathbf{1 b}$ and $\mathbf{1 c}$ show powder which was milled for $1 \mathrm{~h}$ and $18 \mathrm{~h}$ in the Ar atmosphere without a liquid medium, respectively. After 1 $\mathrm{h}$ of the milling, the size of the powder particles did not change much, but their shape changed dramatically. Increasing the milling time up to $18 \mathrm{~h}$ did not result in a further change of the particles shape, but their average size decreased substantially. Irregular shape and fragmentation of the particles imply the introduction of high 
deformation into their matrix. Inspection of the cross-section revealed substantial refinement of the inner structure, which can be seen especially on the secondary phases, cf. Figures $\mathbf{2 a}$ with $\mathbf{2 b}$ and $\mathbf{2 c}$. Change of size and shape of the powder particles was comparable to the previous studies. Interestingly, similar size and morphology of the powder particles were observed in cryo-milled AZ31 with a final grain size of $\sim 30 \mathrm{~nm}$ [5]. The assumption, that cryo-temperatures are not crucial for mechanical milling of magnesium, is supported also by other studies, in which grain size of $\sim 80 \mathrm{~nm}[6]$ and $\sim 40 \mathrm{~nm}$ [4] was achieved in pure magnesium at room temperature. However, transmission electron microscopy needs to be performed in order to confirm or deny comparable grain refinement in our samples.

Milling in the liquid media, in this case ethanol, resulted in a significant change of the milling conditions. As shown above, dry-milling caused severe fragmentation of the powder particles, but eventually, the individual particles were cold-welded together from smaller pieces. This could be seen in Figures $\mathbf{2 b}$ and $\mathbf{2 c}$, where pores and cracks are present in almost all particles. The particles were randomly cold-welded together and to the parts of attritor after each collision and subsequently fragmented again. However, the amount of the powder attached to the stainless-steel balls, shaft and container were significant especially after the longer milling trial, despite utilization of the stearic acid. On the other hand, wet-milling in ethanol resulted in complete suppression of cold-welding even after $18 \mathrm{~h}$ of milling. Consequently, a significant change in the particles' morphology from spherical-like to flake-like was observed, see Figure 1d. It was already shown in various materials including magnesium that mechanical milling of ductile particles could lead to the formation of flake-like morphology [79]. During the milling in the attritor, compression and shear deformation is introduced to the powder particles and they are being flattened. Inspection in SEM revealed that the size of the flakes significantly varies from microns to tens of microns. The inner structure does not look as refined, as in the dry milled samples; nevertheless, it needs to be thoroughly explored by transmission electron microscopy yet.
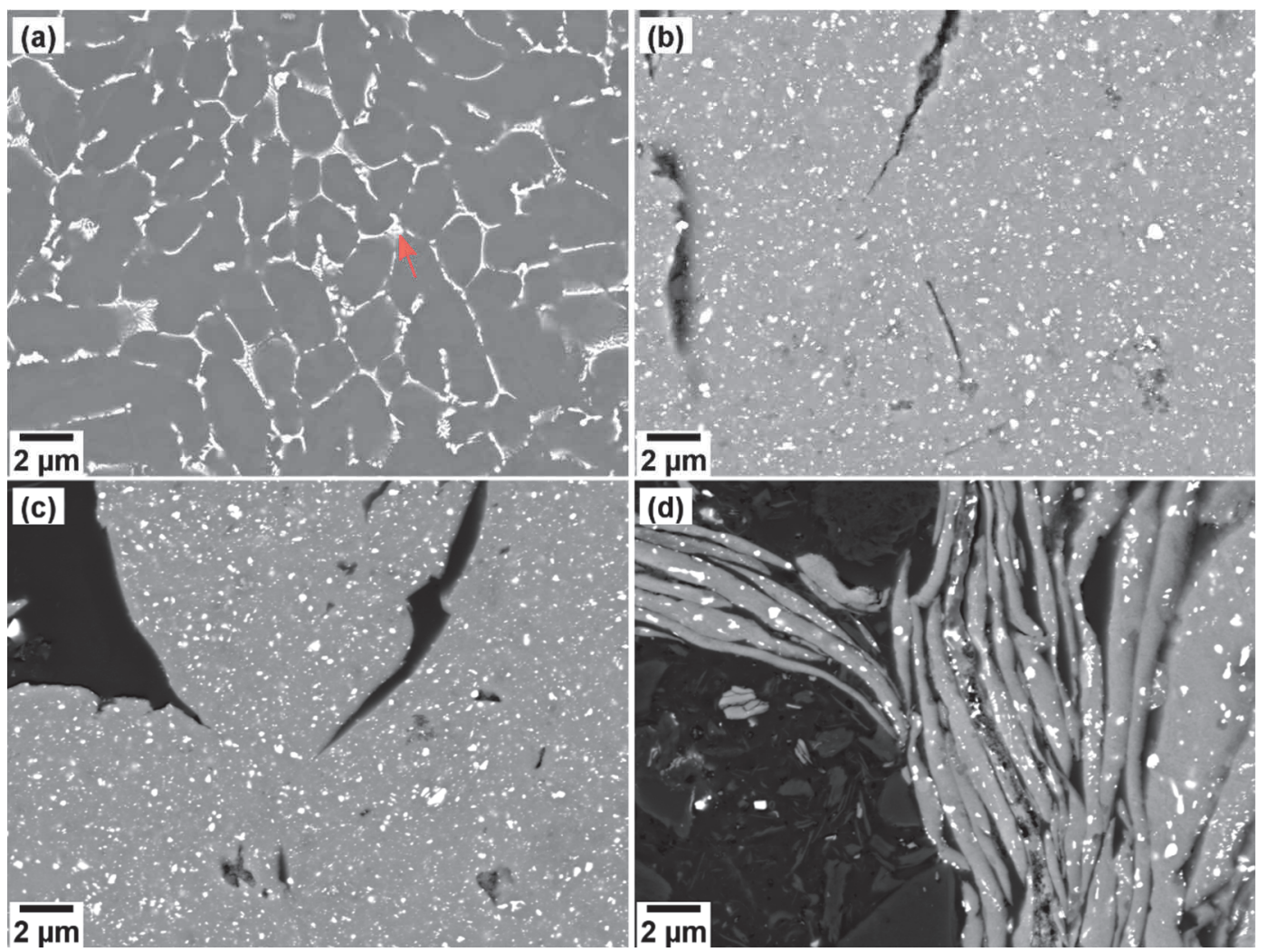

Figure 2 Cross-section of gas-atomized powder (a), powder milled in Ar with SA for $18 \mathrm{~h}$ (c) and in $\mathrm{Ar}$ with $\mathrm{SA}$ and ethanol for $18 \mathrm{~h}(\mathrm{~d})$. 
The other important benefit of mechanical milling is the fragmentation of the surface oxide layer. This layer forms naturally on the particle surface when exposed to air. Usually, passivation is performed on purpose because of safety reasons and thin oxide layer do not cause significant problems during consolidation. However, due to the limited protectiveness of magnesium oxide, more intensive oxidation occurs during passivation and its thickness is several times higher compared to e.g. aluminum [1]. A thicker layer of magnesium oxide hinders diffusion and therefore decreases the effectiveness of the processing. Figure $3 a$ shows magnesium oxide film formed on the gas-atomized particle. Effect of mechanical milling on the oxide film is twofold. First, the film is broken into smaller pieces and is not continuous anymore, and second, amount of oxide is the same after the milling when performed under protective atmosphere, but the overall surface of particles is much larger [6]. The milling in this study was performed under argon atmosphere. Therefore, as shown in Figure 3, a continuous layer of oxide is not present on milled powders and much better sintering effectiveness is expected.
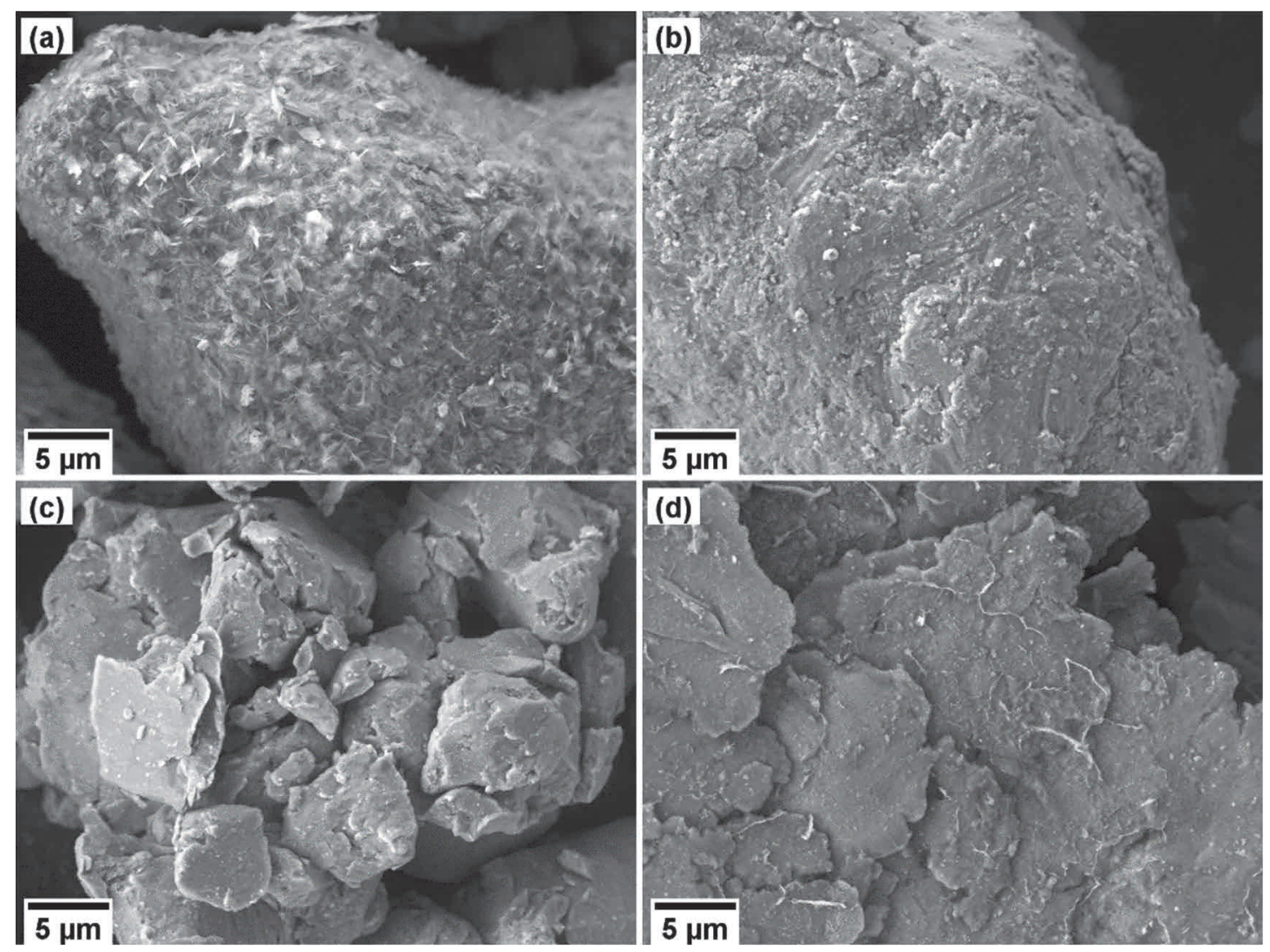

Figure 3 Surface of gas-atomized powder (a), powder milled in Ar with SA for $18 \mathrm{~h}$ (c) and in Ar with SA and ethanol for $18 \mathrm{~h}(\mathrm{~d})$.

\section{CONCLUSION}

The gas-atomized powder prepared from AE42 magnesium alloy was mechanically milled at various conditions. The effect of milling on the size, morphology and particle microstructure was investigated. The following conclusions can be drawn from this study:

- Dry milling at room temperature in argon atmosphere leads to significant refinement of the powder, but the negative effect of cold-welding was observed despite the addition of the process control agent.

- Wet milling in ethanol suppressed the cold-welding and resulted in a significant change of particles morphology from spherical-like to flake-like. 
- $\quad$ The continuous oxide layer present on the gas-atomized particles was successfully disrupted by the mechanical milling.

\section{ACKNOWLEDGEMENTS}

This work was financially supported by the Czech Science Foundation under the project GA18-19213Y. The authors acknowledge additional financial support by the Charles University Grant Agency under the grant 410119.

\section{REFERENCES}

[1] ÜNAL, A. Rapid solidification of magnesium by gas atomization. Materials and Manufacturing Processes. 1992 , vol. 7, no. 3, pp. 441-461. 10.1080/10426919208947431

[2] GUILLON, O., GONZALEZ-JULIAN, J., DARGATZ, B., KESSEL, T., SCHIERNING, G., RÄTHEL J. and HERRMANN, M. Field-Assisted Sintering Technology/Spark Plasma Sintering: Mechanisms, Materials, and Technology Developments. Advanced Engineering Materials. 2014, vol. 16, no. 7, pp. 830-849. 10.1002/adem.201300409

[3] MINÁRIK, P., STRÁSKÝ, J., VESELÝ, J., LUKÁČ, F., HADZIMA, B. and KRÁL, R. AE42 magnesium alloy prepared by spark plasma sintering. Journal of Alloys and Compounds. 2018, vol. 742, pp. 172-179. 10.1016/j.jallcom.2018.01.115

[4] HWANG, S., NISHIMURA, C. and MCCORMICK, P.G. Mechanical milling of magnesium powder. Materials Science and Engineering: A. 2001, vol. 318, no. 1, pp. 22-33. 10.1016/S0921-5093(01)01767-1

[5] GUAN, D., RAINFORTH, W.M., SHARP, J., GAO, J.and TODD, I. On the use of cryomilling and spark plasma sintering to achieve high strength in a magnesium alloy. Journal of Alloys and Compounds. 2016, vol. 688, Part A, pp. 1141-1150. 10.1016/j.jallcom.2016.07.162

[6] KIM, K.R., AHN, J.W., KIM, G.-H., HAN, J.H., CHO, K.K., ROH, J.-S., KIM, W.J. and KIM, H.S. Corrosion behavior of magnesium powder fabricated by high-energy ball milling and spark plasma sintering. Metals and Materials International. 2014, vol. 20, no. 6, pp. 1095-1101. 10.1007/s12540-014-6023-5

[7] KOZLÍK, J., STRÁSKÝ, J., HARCUBA, P., IBRAGIMOV, I., CHRÁSKA, T. and JANEČEK, M. Cryogenic milling of titanium powder. Metals. 2018, vol. 8, no. 1, p. 31. 10.3390/met8010031

[8] UZUN, R.O., DURMUŞ, H., UZUN, R.O. and DURMUŞ, H. Effect of mill type on morphology of AA6013 aluminum powder. Matéria (Rio de Janeiro). 2016, vol. 21, no. 3, pp. 647-654. 10.1590/S1517-707620160003.0062

[9] THEODORE, A., JEON, K.-J. and WU, C.-Y. Flake particle synthesis from ductile metal particles using a novel high-speed vibratory mill. KONA Powder and Particle Journal. 2006, vol. 24, pp. 83-92. 10.14356/kona.2006011 